\title{
Computational modeling of the effects of auditory nerve dysmyelination
}

\author{
Angus M. Brown ${ }^{1}$ and Martine Hamann ${ }^{2 *}$ \\ 1 School of Biomedical Sciences, Queens Medical Centre, University of Nottingham, Nottingham, UK \\ ${ }^{2}$ Department of Cell Physiology and Pharmacology, University of Leicester, Leicester, UK
}

\author{
Edited by: \\ Anderson Mon, University of \\ California San Francisco, USA \\ Reviewed by: \\ James C. Vickers, University of \\ Tasmania, Australia \\ Ping Liu, University of Connecticut \\ Health Center, USA \\ *Correspondence: \\ Martine Hamann, Department of \\ Cell Physiology and Pharmacology, \\ University of Leicester, Medical \\ Sciences Building, PO Box 138, \\ University Road, Leicester \\ LE1 9HN, UK \\ e-mail:mh86@le.ac.uk
}

Our previous study showed that exposure to loud sound leading to hearing loss elongated the auditory nerve (AN) nodes of Ranvier and triggered notable morphological changes at paranodes and juxtaparanodes. Here we used computational modeling to examine how theoretical redistribution of voltage gated $\mathrm{Na}^{+}, \mathrm{Kv} 3.1$, and Kv1.1 channels along the AN may be responsible for the alterations of conduction property following acoustic over-exposure. Our modeling study infers that changes related to $\mathrm{Na}^{+}$channel density (rather than the redistribution of voltage gated $\mathrm{Na}^{+}, \mathrm{Kv} 3.1$, and $\mathrm{Kv1} 1.1$ channels) is the likely cause of the decreased conduction velocity and the conduction block observed after acoustic overexposure (AOE).

Keywords: myelin sheath, hearing loss, node of Ranvier, conduction velocity, conduction block, deafness, myelin domains, action potential

\section{INTRODUCTION}

The rapid conduction of action potentials in both the central nervous system (CNS) and peripheral nervous system (PNS) depends on the myelin sheath around neuronal axons. Myelin plays a passive role by insulating axons. Myelin also plays an active role, allowing for saltatory conduction as action potentials regenerate via active, voltage dependent $\mathrm{Na}^{+}$and $\mathrm{K}^{+}$ionspecific conductances at the intermittent, non-myelinated nodes of Ranvier (Ranvier, 1871; Huxley and Stampfli, 1949; Rasband and Trimmer, 2001). The fundamental importance of myelin is highlighted in demyelinating diseases where the speed of conduction along axons is altered and sensory, motor and/or cognitive ability is severely compromised (Nave, 2010). The auditory nerve (AN) contains mainly myelinated axons projecting from type I spiral ganglion neurons to brainstem cochlear nuclei (Toesca, 1996). We recently showed that acoustic overexposure (AOE) leading to hearing loss also triggered notable morphological changes at AN myelin sub-domains such as nodes of Ranvier, paranodes and juxtaparanodes (Poliak and Peles, 2003) that were associated with the decreased conduction velocity (Tagoe et al., 2014). Specific changes involved a decreased number of lamella wraps and hence myelin thickness, a marked elongation of the nodes and juxtaparanodes, and a retraction of the paranodes (Tagoe et al., 2014). Precise localization of axonal ion channels is crucial for proper electrical and chemical functions of axons. It is unknown whether AOE-induced deficit in conduction velocity (Tagoe et al., 2014) is due to re-distribution of voltagegated channels from specific myelin sub-domains. At the nodes of Ranvier, clusters of voltage-gated sodium channels facilitate saltatory conduction of action potentials (Rasband and Trimmer, 2001; Hedstrom and Rasband, 2006; Leterrier et al., 2010). Kv3.1 voltage-gated potassium $(\mathrm{Kv})$ channels contributing to the ability of auditory neurons to fire at high frequencies (Kanemasa et al., 1995; Macica et al., 2003) are also clustered at the nodes (Devaux et al., 2003). Kv1.1 voltage-gated potassium (Kv) channels reduce action potential jitter (Gittelman and Tempel, 2006) and determine action potential threshold (Brew et al., 2003; Oertel et al., 2008), are clustered in the juxtaparanodal regions ( $\mathrm{Gu}$ and $\mathrm{Gu}$, 2011). Here we modeled changes in the AN conduction properties after AOE based on our recent data (Tagoe et al., 2014) and tested whether the decreased conduction velocity observed after AOE (Tagoe et al., 2014) could also be due to the redistribution of voltage gated $\mathrm{Na}^{+}, \mathrm{Kv} 3.1$ and $\mathrm{Kv} 1.1$ channels.

\section{METHODS \\ COMPUTER SIMULATIONS}

Simulations were carried out using Neuron 7.1 (Hines and Carnevale, 1997) and were based on previously published morphological data on the AN (Tagoe et al., 2014). Briefly, the AN was modeled as a single axon unsheathed by myelin lamellae in a manner similar to that described previously (Kolaric et al., 2013). The axon comprised narrow nodal regions separated by larger internodal regions (INR, Figure 1A). Passive electrical properties were based on data from corpus callosum axons and oligodendrocytes (Bakiri et al., 2011) and voltage dependent conductances were based on previous studies including an existing model of the AN (Kanemasa et al., 1995; Macica et al., 2003) (Figures 1A,B). Current densities were derived from values in Kanemasa et al. (1995) and Macica et al. (2003) where maximum current amplitude was given relative to a cell capacitance $(\mathrm{Cm})$, based on a specific $\mathrm{Cm}$ of $1 \mu \mathrm{F} . \mathrm{cm}^{-2}$. The simulated action potentials were computed using backward Euler integration with a time step of $10 \mathrm{~ms}$. Our morphological measurements lack a value for the internodal length, thus we chose an intermediate value from two 


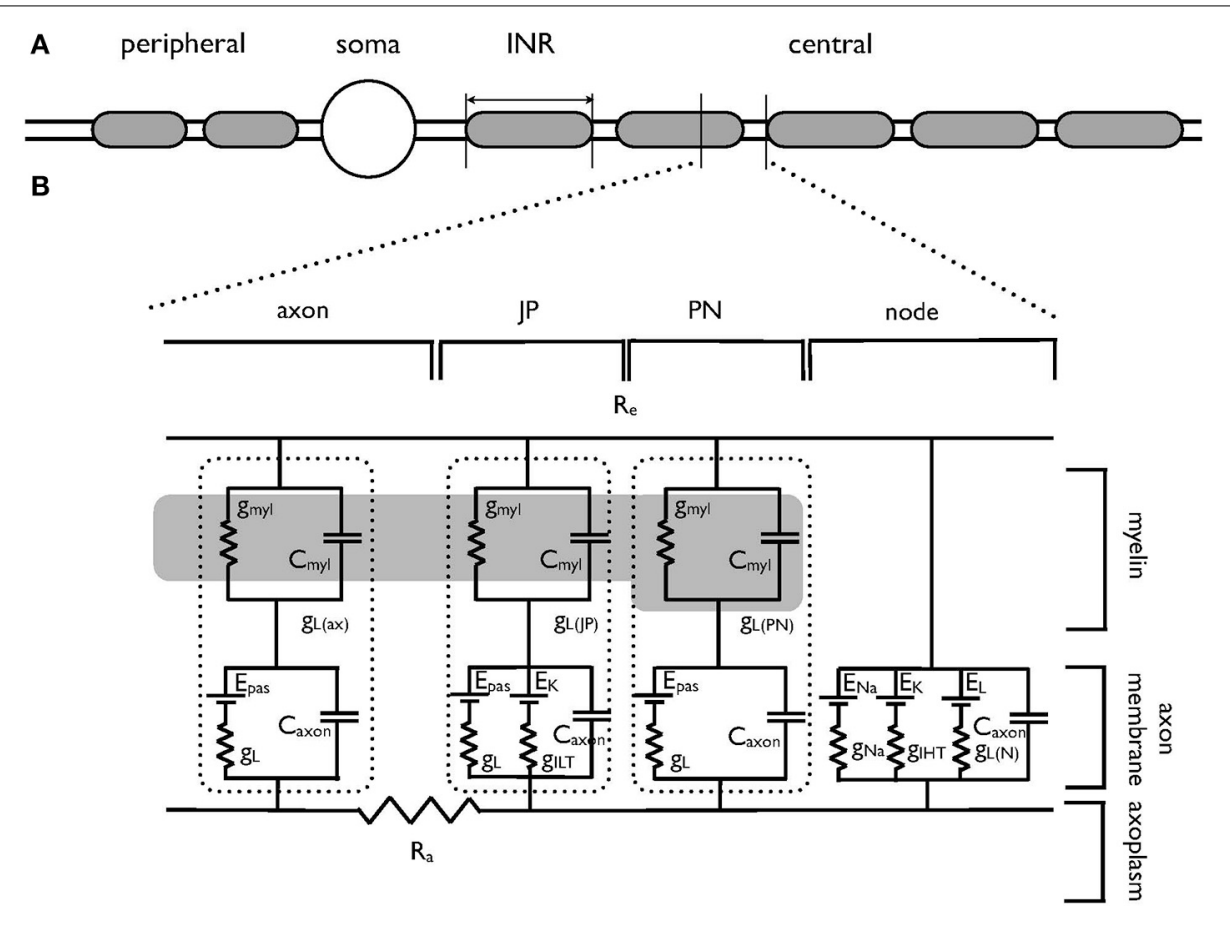

FIGURE 1 | Schematic model of the auditory nerve. (A) The auditory nerve fiber is divided into three distinct regions. The peripheral axonal region terminates in the organ of Corti. The soma resides in the spiral ganglion. The central axon projects to the cochlear nucleus, is myelinated with internodal myelinated regions modeled as $100 \mu \mathrm{m}$ in length. (B) Equivalent circuit of the central portion of the auditory nerve, which has been adapted from an existing model of corpus callosum axon (Tagoe et al., 2014). The morphological and electrical values are contained in Tables 1, 2 respectively. The axon is divided into the nodal region and the internodal region. The internodal region is subdivided into the paranodal (PN) juxtaparanodal (JP) and axonal regions (axon). The nodal region expresses the voltage-dependent conductances of the $I_{\mathrm{Na}}\left(g_{\mathrm{Na}}\right)$ and $\mathrm{I}_{\mathrm{HT}}\left(\mathrm{g}_{\mathrm{IHT}}\right)$ currents as well as a leak current (gL). Gi $i_{L T}$ is expressed in the JP. The axolemma of the internodal regions expresses a leak current $\left(g_{\llcorner}\right)$, as does the overlying myelin $\left(g_{m y l}\right)$. The dotted lines enclose the leak and capacitative properties of each INR component. Internal resistance $\left(R_{a}\right)$ is constant throughout the model and external resistance $\left(R_{e}\right)$ is zero. The dark region represents the myelin, and only one PN and JP abutting the node are shown for clarity. $g_{m y l}$ and $C_{m y l}$ are the passive conductance and capacitance across the myelin, respectively. $g_{L}$ is the passive conductance, $g_{L(N)}$ refers to the passive conductance at the node, $E_{\text {pas }}$ is the reversal potential for the passive conductance $\left(V_{L}\right)$, and $E_{N a}$ and $E_{K}$ are the reversal potentials for the $\mathrm{Na}^{+}$current and ILT and IHT respectively. existing models of AN (Rattay et al., 2001; Smit et al., 2010) of $100 \mu \mathrm{m}$.

\section{MORPHOLOGICAL VALUES}

The morphological dimensions of the axonal compartments have recently been published (Tagoe et al., 2014). The model of the control axon comprised alternating nodal and internodal regions (INR). The INRs were subdivided into paranodal (PN), juxtaparanodal (JP) and axonal compartments (Figure 2A), such that each INR comprised two PNs, each abutting consecutive nodal regions, two JP regions located between the $\mathrm{PN}$ and a central axonal portion (Figure 2A). The dimensions of the compartments are contained in Table 1. AOE changed the nodal length and diameter from 1.3 to $6.15 \mu \mathrm{m}$ and 0.8 to $1.28 \mu \mathrm{m}$, respectively; the PN length and diameter from 2.34 to $1.52 \mu \mathrm{m}$ and 0.75 to $1.23 \mu \mathrm{m}$ respectively and the JP length and diameter from 5.14 to $6.23 \mu \mathrm{m}$ and 2.13 to $1.32 \mu \mathrm{m}$ respectively (Tagoe et al., 2014). The model contained a fast sodium current $\left(\mathrm{I}_{\mathrm{Na}}\right)$, a high threshold $\left(\mathrm{I}_{\mathrm{HT}}\right) \mathrm{Kv} 3.1$ potassium current, a low threshold $\left(\mathrm{I}_{\mathrm{LT}}\right)$ Kv1.1 potassium current and a leak current $\left(\mathrm{I}_{\mathrm{L}}\right)$. We assumed that the current density for $\mathrm{I}_{\mathrm{Na}}$ and $\mathrm{I}_{\mathrm{HT}}$ in the nodal region were $6.6 \mathrm{mS} . \mathrm{cm}^{-2}$ and $1.98 \mathrm{mS} . \mathrm{cm}^{-2}$, respectively, and the value for $\mathrm{I}_{\mathrm{LT}}$ in the $\mathrm{PN}$ was $2.13 \mathrm{mS} . \mathrm{cm}^{-2}$ (Kanemasa et al., 1995).

We used these morphological changes to determine conduction properties under two conditions. Firstly, we modeled the effect of altering current distributions such that the compartments resulting from $\mathrm{AOE}$ treatment contained the same number of channels, but the density of these channels was altered to reflect an even distribution of the channels along the altered nodal, PN and JP length (AOE1 condition illustrated in Figure 3A). This condition named AOE1 resulted in morphological values contained in Table 1. Secondly, we modeled the axon as if the channels had remained in place and did not encroach on the AOE-induced changes in compartment size (AOE2 condition illustrated in Figure 3A). In this condition, the nodal compartment had the same altered dimensions as the nodal compartment in AOE1. However, the expression of $\mathrm{I}_{\mathrm{Na}}$ and $\mathrm{I}_{\mathrm{HT}}$ remained the same as the control condition. In AOE2 the regions $\mathrm{n} 1$ contained no voltage dependent channels and were sized such that the combined values of the two $n 1$ regions and the nodal region equaled the value of the nodal region in Table 1. Similar calculations were carried out for the PN and JP and considered the PN length decrease the JP length increase after AOE (Tagoe et al., 2014). 


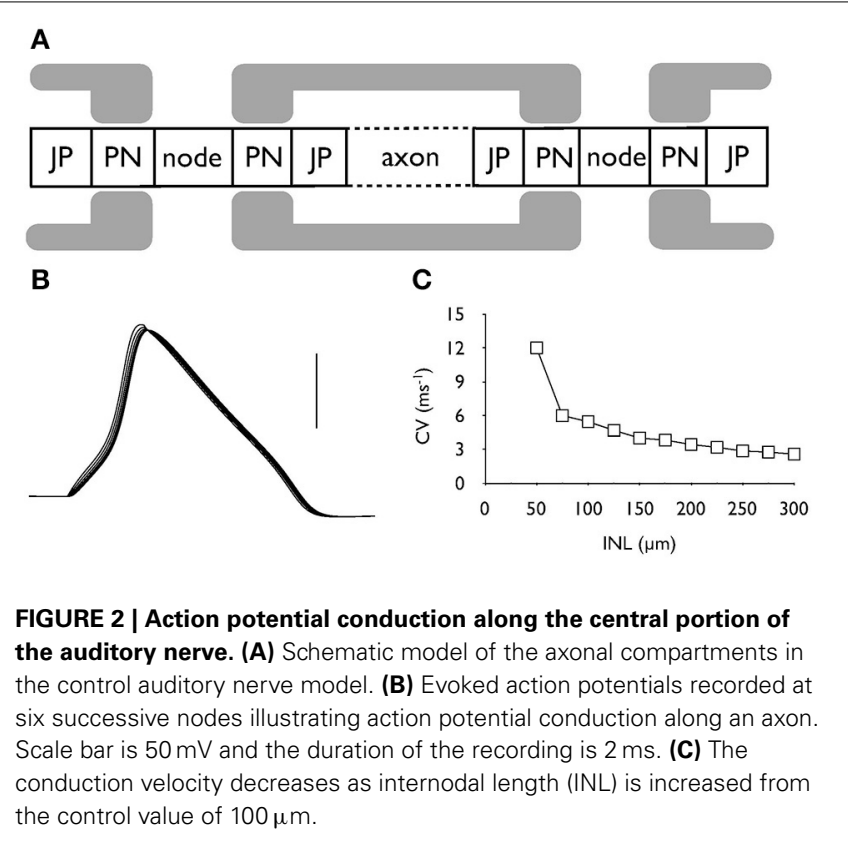

Table 1 | Morphological parameters of the auditory nerve in control and in the two simulated AOE conditions.

\begin{tabular}{|c|c|c|c|c|c|c|}
\hline & Node & n1 & PN & JP & j1 & Axon \\
\hline \multicolumn{7}{|c|}{ CONTROL } \\
\hline I ( $\mu \mathrm{m})$ & 1.3 & - & 2.34 & 5.14 & - & 10.46 \\
\hline$d(\mu \mathrm{m})$ & 0.8 & - & 0.75 & 2.13 & - & 1.25 \\
\hline \multicolumn{7}{|l|}{ AOE1 } \\
\hline I ( $\mu \mathrm{m})$ & 6.15 & - & 1.52 & 6.23 & - & 9.79 \\
\hline$d(\mu \mathrm{m})$ & 1.28 & - & 1.23 & 1.32 & - & 1.25 \\
\hline \multicolumn{7}{|l|}{ AOE2 } \\
\hline I $(\mu \mathrm{m})$ & 1.3 & 2.425 & 2.34 & 5.14 & 1.09 & 9.79 \\
\hline$d(\mu \mathrm{m})$ & 1.28 & 1.28 & 1.23 & 2.13 & 1.16 & 1.25 \\
\hline
\end{tabular}

Morphological dimensions of the various compartments illustrated in Figures $\mathbf{2 A}, \mathbf{3 A}$, where $I$ and $d$ refer to length and diameter and p/j/a refer to paranodal, juxtaparanodal and axonal compartments. Axon dimensions are taken from previously published data Kolaric et al. (2013). The length indicates the compartments length of the axon used in the model with 20 compartments per internodal length.

Each INR was divided into compartments such that the length of each compartment was less than $0.1 \lambda$ (length constant), to ensure each compartment was isopotential, the generally accepted practice in such simulations (Carnevale and Hones, 2006; Sterratt et al., 2011). The length constant $(\lambda)$ was calculated as:

$$
\lambda=\sqrt{\frac{\operatorname{rad} * \mathrm{R}_{\mathrm{m}}}{2 * \mathrm{R}_{\mathrm{a}}}}
$$

where rad is the axon radius, $R_{a}$ is the axoplasmic resistance and $\mathrm{R}_{\mathrm{m}}$ is the membrane resistance.

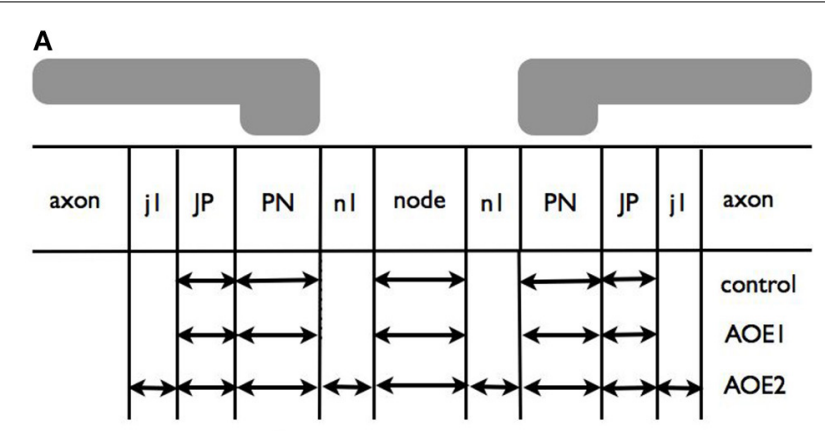

B
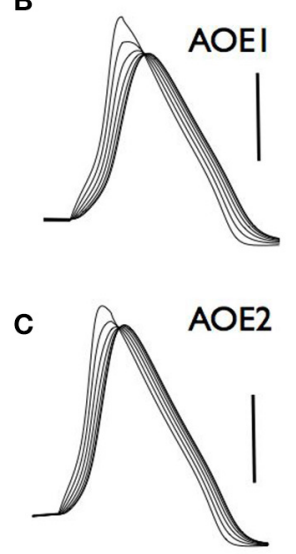

D

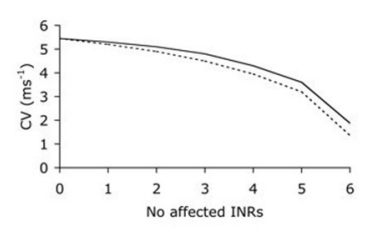

E

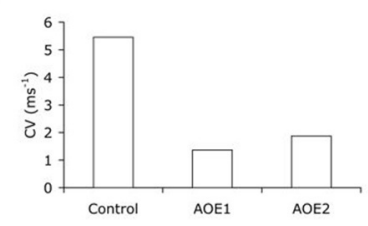

FIGURE 3 | Auditory overexposure decreases conduction velocity. (A) Schematic model of the central portion of the auditory nerve after AOE, illustrating the morphological changes incurred by the nerve. See Table 2 for dimensions of compartments. (B,C). Action potentials evoked from six successive nodes after AOE1 (B) or AOE2 (C) treatment demonstrated a decrease in the conduction velocity. Scale bars $50 \mathrm{mV}$ in $\mathbf{B}$ and $\mathbf{C}$ and duration of recording is same as Figure 2B. (D) Incremental decrease in conduction velocity as more INRs are affected by AOE-induced dysmyelination in AOE1 (dotted line) and AOE2 (line) models. (E) Conduction velocity (with an INL of $100 \mu \mathrm{m}$ ) decreases as a result of both AOE1 and AOE2 (see Methods for details).

Table 2 | Passive properties of the auditory nerve in control and after AOE.

\begin{tabular}{lcc}
\hline & Control & AOE \\
\hline $\mathrm{Cm}_{\mathrm{p} / \mathrm{j} / \mathrm{a}}\left(\mu \mathrm{F} . \mathrm{cm}^{-2}\right)$ & 0.0184 & 0.0290 \\
$\mathrm{Cm}_{\text {node }}(\mathrm{pF})$ & 0.0327 & 0.247 \\
$\mathrm{Cm}$ INR $(\mathrm{pF})$ & 0.136 & 0.167 \\
$\mathrm{gL}$ node $\left(\mathrm{mS} . \mathrm{cm}^{-2}\right)$ & 0.2 & 0.2 \\
$\mathrm{gL}$ p/j/a $\left(\mu \mathrm{S} . \mathrm{cm}^{-2}\right)$ & 10.89 & 20.3 \\
\hline
\end{tabular}

Passive properties of nodal and INR compartments in control and AOE treated nerves. p/j/a refers to paranodal, juxtaparanodal and axonal regions, all of which express the same values. $G$ refers to conductance and $\mathrm{Cm}$ to capacitance. The capacitance and leak current were calculated for each individual INR and node demonstrating that AOE causes an increased INR capacitance due to decreased myelin wraps and increased nodal capacitance and leak current.

\section{PASSIVE MEMBRANE PROPERTIES}

The basic passive properties and the methods used to calculate these properties have previously been described in detail (Kolaric et al., 2013). The value of axoplasmic resistance (Ra) was $70 \Omega . c m$ 
throughout. Cm was assumed to be $1 \mu \mathrm{F} . \mathrm{cm}^{-2}$ and nodal $\mathrm{g}_{\mathrm{L}}$ was $0.2 \mathrm{mS} . \mathrm{cm}^{-2}$. In the model the control axon had 23.7 lamella wraps of myelin, whereas AOE decreased the number to 15.8 (Tagoe et al., 2014). The values were rounded-up to the nearest whole number to ease computations.

\section{VOLTAGE-DEPENDENT CONDUCTANCES}

The model described in Hodgkin and Huxley (1952a,b,c) contained a fast sodium current $\left(\mathrm{I}_{\mathrm{Na}}\right)$, a high threshold $\left(\mathrm{I}_{\mathrm{HT}}\right) \mathrm{Kv} 3.1$ potassium current, a low threshold $\left(\mathrm{I}_{\mathrm{LT}}\right) \mathrm{Kv} 1.1$ potassium current and a leak current $\left(\mathrm{I}_{\mathrm{L}}\right)$. $\mathrm{I}_{\mathrm{Na}}$ and $\mathrm{I}_{\mathrm{HT}}$ were located at the nodal regions and $\mathrm{I}_{\mathrm{LT}}$ was located at the JPN (7).

The voltage dependence of the $\mathrm{I}_{\mathrm{HT}}$ was described by:

$$
\mathrm{I}_{\mathrm{HT}}=\mathrm{g}_{\mathrm{K}} \mathrm{n}^{3}(1-\gamma+\gamma \mathrm{p})\left(\mathrm{V}_{\mathrm{m}}-\mathrm{V}_{\mathrm{HT}}\right)
$$

where $0>\gamma>1$, and the variables $p$ and $n$ are described by $\mathrm{dj} / \mathrm{dt}=\alpha_{\mathrm{j}}(1-\mathrm{j})-\beta_{\mathrm{j}}$ where $j=n$ or $p$, and is calculated by $\alpha_{j}=k_{\alpha j} \exp \left(\eta_{\alpha j} . V\right)$ and $\beta_{j}=k_{\beta j} \exp \left(\eta_{\beta j} . V\right)$.

$\mathrm{k}_{\alpha \mathrm{j}}, \mathrm{k}_{\beta \mathrm{n}}, \eta_{\alpha \mathrm{j}}$ and $\eta_{\beta \mathrm{j}}$ determine the rate and voltage dependence respectively of current activation with the values required to calculate the rate constants contained in Table 3.

The voltage dependent currents $\mathrm{I}_{\mathrm{Na}}$ and $\mathrm{I}_{\mathrm{LT}}$ were described by:

$$
\begin{aligned}
& \mathrm{I}_{\mathrm{Na}}=\mathrm{g}_{\mathrm{Na}} \mathrm{m}^{3} \mathrm{~h}\left(\mathrm{~V}_{\mathrm{m}}-\mathrm{V}_{\mathrm{Na}}\right) \\
& \mathrm{I}_{\mathrm{LT}}=\mathrm{g}_{\mathrm{K}} \operatorname{lr}\left(\mathrm{V}_{\mathrm{m}}-\mathrm{V}_{\mathrm{LT}}\right)
\end{aligned}
$$

where I is the current per unit area and $\mathrm{g}$ is the voltage dependent conductance where $\mathrm{g}_{\mathrm{Na}}=0.05 \mathrm{~S} . \mathrm{cm}^{-2}, \mathrm{~g}_{\mathrm{HT}}=0.015 \mathrm{~S} . \mathrm{cm}^{-2}$ and $\mathrm{g}_{\mathrm{LT}}=0.002 \mathrm{~S} . \mathrm{cm}^{-2} . \mathrm{V}_{\mathrm{m}}$ is the membrane potential and $\mathrm{V}$ refers to the reversal potential whereby $\mathrm{V}_{\mathrm{HT}}=\mathrm{V}_{\mathrm{LT}}=-80 \mathrm{mV}$ and $\mathrm{V}_{\mathrm{Na}}=50 \mathrm{mV}$.

The leak current was calculated as $\mathrm{I}_{\mathrm{L}}=\mathrm{g}_{\mathrm{L}}\left(\mathrm{V}_{\mathrm{m}}-\mathrm{V}_{\mathrm{L}}\right)$, where $\mathrm{g}_{\mathrm{L}}=0.2 \mathrm{mS} . \mathrm{cm}^{-2}$ and $\mathrm{V}_{\mathrm{L}}=-63 \mathrm{mV}$.

The variables $m, h, r$ and $l$ are associated with channel activation $(m, l)$ and inactivation $(h, r)$ and are calculated as

\begin{tabular}{|c|c|c|c|c|}
\hline & $\alpha_{n}$ & $\beta_{\mathbf{n}}$ & $\alpha_{\mathbf{p}}$ & $\beta_{\mathbf{p}}$ \\
\hline $\mathrm{k}_{(I H T)}$ & $0.2719 \mathrm{~ms}^{-1}$ & $0.1974 \mathrm{~ms}^{-1}$ & $0.00713 \mathrm{~ms}^{-1}$ & $0.0935 \mathrm{~ms}^{-1}$ \\
\hline \multirow[t]{2}{*}{$\eta_{(\mathrm{IHT})}$} & $0.04 \mathrm{mV}^{-1}$ & $0 \mathrm{mV}^{-1}$ & $-0.1942 \mathrm{mV}^{-1}$ & $0.0058 \mathrm{mV}^{-1}$ \\
\hline & $\alpha_{1}$ & $\beta_{\mathbf{I}}$ & $\alpha_{r}$ & $\beta_{\mathbf{r}}$ \\
\hline$k_{(I L T)}$ & $1.2 \mathrm{~ms}^{-1}$ & $0.2248 \mathrm{~ms}^{-1}$ & $0.0438 \mathrm{~ms}^{-1}$ & $0.0562 \mathrm{~ms}^{-1}$ \\
\hline \multirow[t]{2}{*}{$\eta_{(I L T)}$} & $0.03512 \mathrm{mV}^{-1}$ & $-0.0319 m V^{-1}$ & $-0.0053 m V^{-1}$ & $-0.0047 \mathrm{mV}^{-1}$ \\
\hline & $\alpha_{m}$ & $\beta_{m}$ & $\alpha_{h}$ & $\beta_{\mathrm{h}}$ \\
\hline $\mathrm{k}_{(\mathrm{INa})}$ & $76.4 \mathrm{~ms}^{-1}$ & $0.0381 \mathrm{~ms}^{-1}$ & $0.00013 \mathrm{~ms}^{-1}$ & $1.999 \mathrm{~ms}^{-1}$ \\
\hline$\eta_{(\mathrm{INa})}$ & $0.037 \mathrm{mV}^{-1}$ & $-0.043 \mathrm{mV}^{-1}$ & $-0.1216 m V^{-1}$ & $0.0384 \mathrm{mV}^{-1}$ \\
\hline
\end{tabular}

Table 3 | Rate constant parameters of potassium and sodium conductances.

Rate constant parameters of the voltage dependent conductances derived from historical data Kanemasa et al. (1995). (IHT) and (ILT) refer to the high and low threshold $\mathrm{K}^{+}$currents respectively. The rate constants are calculated based on the terminology used by Kanemasa et al. (1995), where $\alpha_{n}=k_{\alpha j} \exp \left(\eta_{\alpha j} . V\right)$ and $\beta_{n}=k_{\beta j} \exp \left(\eta_{\beta j} V\right)$ etc. $\mathrm{dj} / \mathrm{dt}=\alpha_{\mathrm{j}}(1-\mathrm{j})-\beta_{\mathrm{j}}$ where $j=1, r, m$ or $h$. The rate and voltage dependence respectively of $\mathrm{I}_{\mathrm{Na}}$ and $\mathrm{I}_{\mathrm{LT}}$ are calculated in a similar manner to $\mathrm{I}_{\mathrm{HT}}$ with the parameters for calculating $\mathrm{I}_{\mathrm{LT}}$ and $\mathrm{I}_{\mathrm{Na}}$ contained in Table 3.

\section{CONDUCTION VELOCITY}

The model comprised 7 alternating nodal and internodal regions and conduction velocity was calculated between the first (node 0 ) and last node (node 6). When the conduction velocity was reported in function of the number of INRs affected (Figure 3D), the conduction velocity at node 0 was equivalent to the control condition.

\section{RESULTS}

\section{ACTION POTENTIAL CONDUCTION}

The model comprising 7 alternating nodal and internodal regions was capable of firing action potentials in response to injected current. Action potentials were recorded at 6 sequential nodes and data clearly showed that action potentials were propagating from node to node (Figure 2B). As we have no measure of INR length (INL) from our morphological data we estimated $100 \mu \mathrm{m}$ as a reasonable guess as this lies between values from two previous reports (Rattay et al., 2001; Smit et al., 2010). The conduction velocity in control condition was calculated as $5.45 \mathrm{~ms}^{-1}$. (with an INL of $100 \mu \mathrm{m}$ and a calculated length constant $(\lambda)$ for the control axon of about $200 \mu \mathrm{m}$, Figure 2C). Increasing INL caused a decrease in conduction velocity as the INL extended beyond $100 \mu \mathrm{m}$ (Figure 2C).

\section{AOE-INDUCED DECREASE IN CONDUCTION VELOCITY}

We adjusted the model to take into account the morphological changes that occur because of AOE. In our first simulation of the effects of AOE (AOE1) we altered the current density that would result from altered distribution of channels along the node and JPN (see Methods for details). We found that there was a significant effect on action potential propagation (Figure 3B) compared to control (Figure 2B) resulting in a decreased conduction velocity (Figures 3D,E). The results illustrated in Figure 3D derive from simulations where we imposed the AOE-induced dysmyelination on increasing numbers of adjacent INRs in the model. Incrementally increasing the number of INRs affected by AOE dysmyelination showed a non-linear decrease in conduction velocity that steeply decreased with increasing number of INRs affected, as previously described in the corpus callosum model (Kolaric et al., 2013).

In the second simulation we modeled unchanged current density and channel distribution as a result of AOE (AOE2, see Methods). Similarly to AOE1, we found that there was a significant effect on action potential propagation (Figures $3 \mathrm{~B}, \mathrm{C}$ ) compared to control condition (Figure 2B). Conduction velocity was similarly decreased in AOE2 and AOE1 (Figure 3E) and the decreased conduction velocity was more apparent as the number of adjacent INRs affected increased (Figure 3D).

\section{ABSENCE OF EFFECT OF AOE ON FIRING FREQUENCY}

Repetitive firing was induced in the control model by injecting a current pulse of $0.35 \mathrm{nA}$ for a duration of $200 \mathrm{~ms}$ (Figure 4A). 
The resulting action potentials showed regular firing pattern, i.e., a lack of adaptation. Increasing the stimulus intensity resulted in increased frequency of firing, although at higher stimulus intensities the action potentials became much smaller. Imposing the same stimulus on the AOE1 and AOE2 models had a negligible effect of firing frequency (Figure 4B).

\section{EFFECTS OF gNa EXPRESSION ON CONDUCTION VELOCITY}

Decreasing the density of $\mathrm{Na}^{+}$channel expression by attenuating the value of gNa caused a non-linear decrease in conduction velocity until conduction block occurred at a value of about $35 \%$ of control (Figure 5A). The passive leak conductance across the node (gL) under control and both AOE conditions are superimposed to show there are slight effects on $\mathrm{gL}$ as a result of $\mathrm{AOE}$ but these differences are minimal (Figure 5B) and do not indicate increased shunting of current via the node.

\section{DISCUSSION}

The present computer simulations are based on our previous morphological data on the AN (Tagoe et al., 2014). We have shown that the conduction velocity was dependent on the INR length as previously described in the corpus callosum model (Kolaric et al., 2013) and this over a range of between 0.05 and $0.3 \mathrm{~mm}$. Our estimated conduction velocities of the AN in the

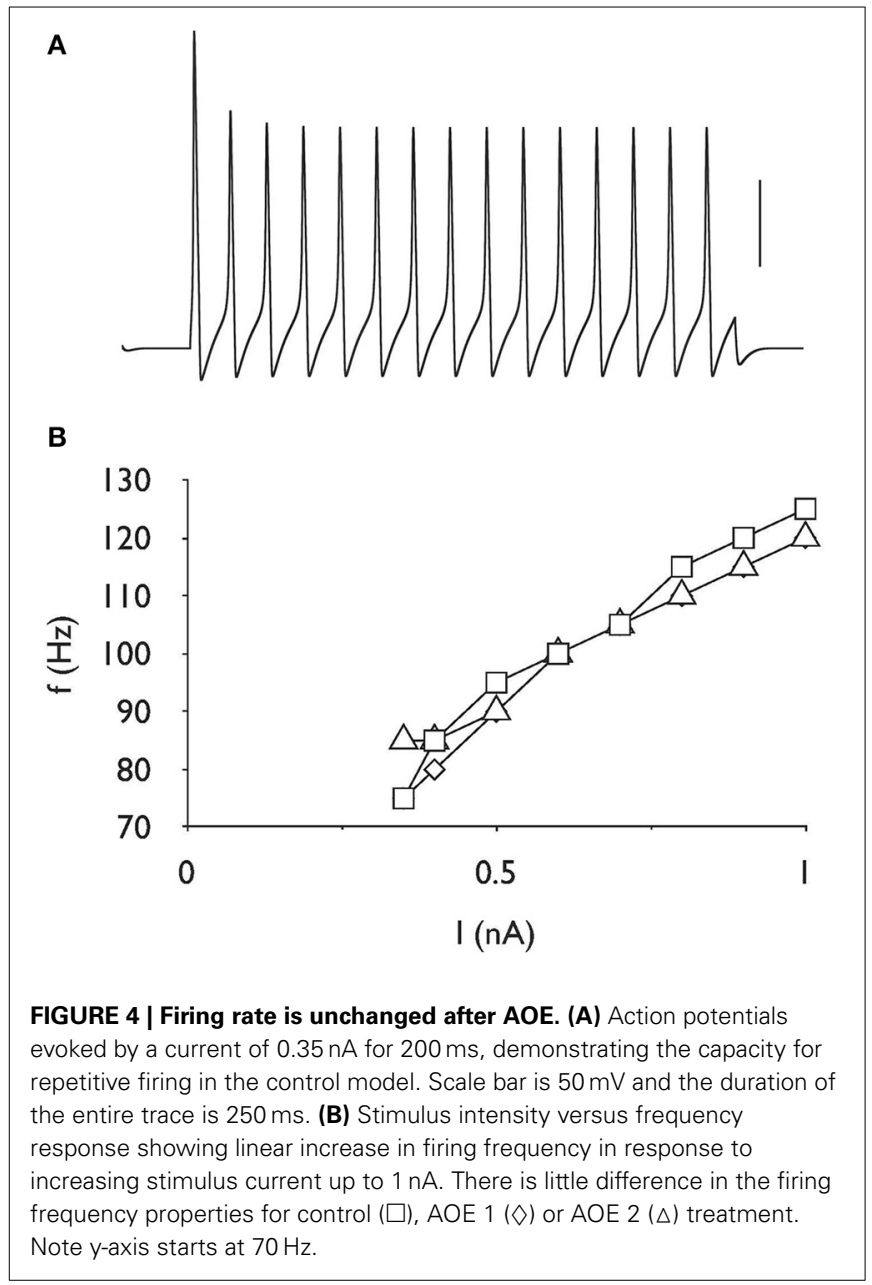

range of 2-12 m.s ${ }^{-1}$ were similar to values (6-14 m.s $\left.{ }^{-1}\right)$ reported for the AN (Poma et al., 2008; Imennov and Rubinstein, 2009). Huxley and Stampfli (1949) suggested that the conduction velocity in myelinated nerve fibers should reach a maximum at a particular internode distance, and that the maximum should be relatively flat (Huxley and Stampfli, 1949). We also found that the conduction velocity in myelinated AN fibers did not increase linearly with increasing internodal length and reached a plateau at an internodal length of $0.3 \mathrm{~mm}$. Our previous field potential recordings of the AN estimated its conduction velocity at $3 \mathrm{~m} . \mathrm{s}^{-1}$ (Tagoe et al., 2014). Although this lower range of values could be due to an AN internodal length of around $200 \mu \mathrm{m}$, it is likely to be due to the recruitment of lower conduction velocity fibers while recording compound action potentials.

Our previous study showed that dysmyelination of the AN resulted in the decrease of the myelin thickness, a marked elongation of nodes of Ranvier and juxtaparanodes, and a retraction of paranodes, slowing the AN conduction velocity by about 3-fold (Tagoe et al., 2014). Using the same morphological values as in Tagoe et al. (2014) and keeping the internodal length of $100 \mu \mathrm{m}$ (Rattay et al., 2001; Smit et al., 2010) constant, we have reproduced here a 3 -fold slowing of conduction velocity. This result was anticipated considering that the elongation of the node would increase its capacitance and decrease its resistance, and therefore

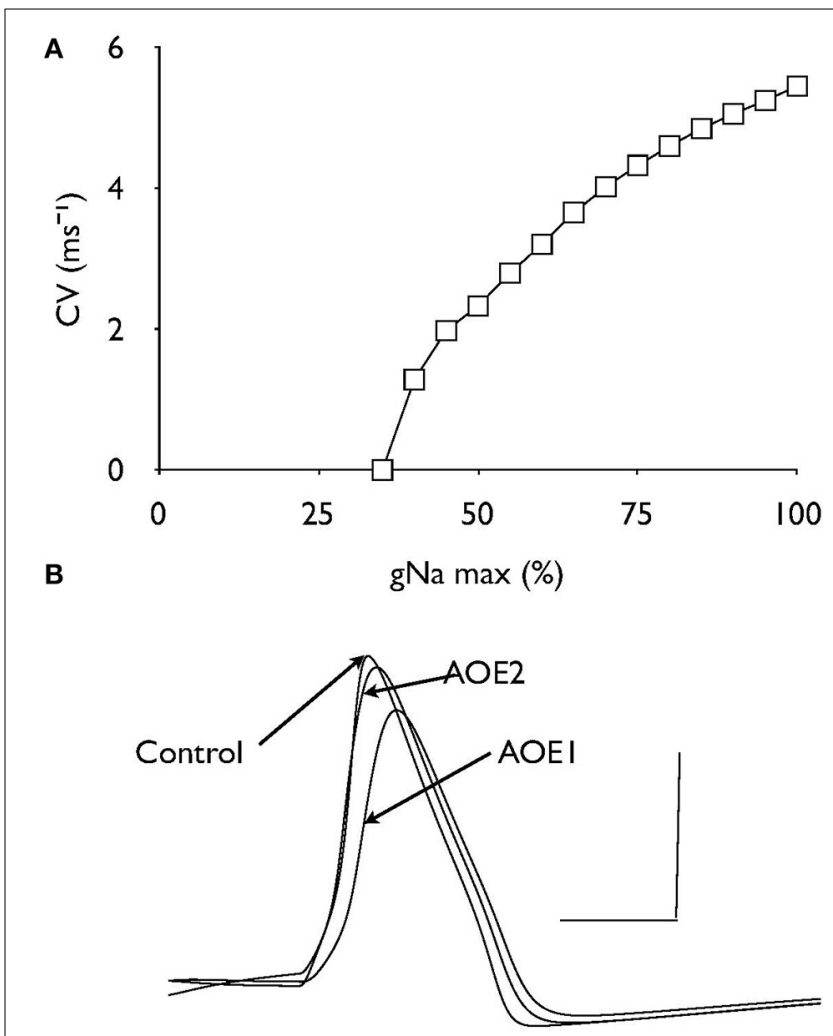

FIGURE 5 | The effect of $\mathbf{g N a}$ on conduction velocity. (A) Decreasing the value of $\mathrm{gNa}$ relative to the control value as $100 \%$ resulted in a non-linear decrease in conduction velocity. (B) Nodal recordings of $\mathrm{gL}$ under control and AOE treated conditions. Scale bars $0.01 \mathrm{nA}$ and $1 \mathrm{~ms}$. 
increase the time to reach the threshold contributing to lower conduction velocity (Hartline and Colman, 2007). The decreased conduction velocity was more apparent with the number of INR affected, as the increased nodal surface area resulted in a decreased current density, increased nodal and INR capacitances (Table 2). As the conduction velocity decreases with increasing length of dysmyelinated axon, we would anticipate conduction block for distances exceeding $700 \mu \mathrm{m}$ (Figure 3D) as a significant length of axon would be affected. Conduction block has indeed been observed for distances exceeding $1 \mathrm{~mm}$ (Tagoe et al., 2014).

Nodal clusters of voltage-gated $\mathrm{Na}^{+}$channels are lost after demyelination, but reappear after remyelination (DugandzijaNovakovic et al., 1995; Novakovic et al., 1996). Similarly, juxtaparanodal Kv1.1 and Kv1.2 channels disperse after demyelination and reorganize with remyelination (Rasband et al., 1998). Deficits of myelin subdomains along the AN could therefore alter spatial segregation of voltage-gated channels and impair the action potential propagation (Peles and Salzer, 2000; Hossain et al., 2005). However we found that spatial segregation of nodal $\mathrm{Na}^{+}$ and Kv3.1 channels or juxtaparanodal Kv1.1 channels had a minimal impact on AN conduction velocity. Axonal targeting of Kv3.1 channels is critical to enable neurons to fire action potentials at the maximal frequency ( $\mathrm{Gu}$ et al., 2012). Our study further suggests that the re-localization of Kv3.1 channels is unlikely to affect action potential firing frequency during AN dys-myelination. Axonal demyelination has been shown to decrease nodal expression of $\mathrm{I}_{\mathrm{Na}}$ (Craner et al., 2004). Our computational analysis indicates that decreasing the $\mathrm{Na}^{+}$channel density has a negative impact on the conduction velocity and that decreasing the $\mathrm{Na}^{+}$ channel density by $65 \%$ relative to control values can fully account for the conduction block observed after AOE.

In conclusion the AOE induced morphological alterations of myelin sub-domains and changes of density of $\mathrm{Na}^{+}$channels are the likely cause of the decreased conduction velocity of the AN and the conduction block observed for distances exceeding $1 \mathrm{~mm}$ (Tagoe et al., 2014)

\section{ACKNOWLEDGMENTS}

We thank Paul Glynn for reviewing the manuscript and Action on Hearing Loss for funding this project.

\section{REFERENCES}

Bakiri, Y., Karadottir, R., Cossell, L., and Attwell, D. (2011). Morphological and electrical properties of oligodendrocytes in the white matter of the corpus callosum and cerebellum. J. Physiol. 589, 559-573. doi: 10.1113/jphysiol.2010. 201376

Brew, H. M., Hallows, J. L., and Tempel, B. L. (2003). Hyperexcitability and reduced low threshold potassium currents in auditory neurons of mice lacking the channel subunit Kv1.1. J. Physiol. 548, 1-20. doi: 10.1113/jphysiol.2002.035568

Carnevale, N. T., and Hones, M. L. (2006). The NEURON Book. Cambridge: Cambridge University Press. doi: 10.1017/CBO9780511541612

Craner, M. J., Newcombe, J., Black, J. A., Hartle, C., Cuzner, M. L., and Waxman, S. G. (2004). Molecular changes in neurons in multiple sclerosis: altered axonal expression of Nav1.2 and Nav1.6 sodium channels and $\mathrm{Na}+/ \mathrm{Ca} 2+$ exchanger. Proc. Natl. Acad. Sci. U.S.A. 101, 8168-8173. doi: 10.1073/pnas.0402765101

Devaux, J., Alcaraz, G., Grinspan, J., Bennett, V., Joho, R., Crest, M., et al. (2003). Kv3.1b is a novel component of CNS nodes. J. Neurosci. 23, 4509-4518.

Dugandzija-Novakovic, S., Koszowski, A. G., Levinson, S. R., and Shrager, P. (1995). Clustering of $\mathrm{Na}+$ channels and node of Ranvier formation in remyelinating axons. J. Neurosci. 15, 492-503.
Gittelman, J. X., and Tempel, B. L. (2006). Kv1.1-containing channels are critical for temporal precision during spike initiation. J. Neurophysiol. 96, 1203-1214. doi: 10.1152/jn.00092.2005

Gu, Y., Barry, J., McDougel, R., Terman, D., and Gu, C. (2012). Alternative splicing regulates kv3.1 polarized targeting to adjust maximal spiking frequency. J. Biol. Chem. 287, 1755-1769. doi: 10.1074/jbc.M111.299305

$\mathrm{Gu}, \mathrm{C}$., and $\mathrm{Gu}$, Y. (2011). Clustering and activity tuning of Kvl channels in myelinated hippocampal axons. J. Biol. Chem. 286, 25835-25847. doi: 10.1074/jbc.M111.219113

Hartline, D. K., and Colman, D. R. (2007). Rapid conduction and the evolution of giant axons and myelinated fibers. Curr. Biol. 17, R29-R35. doi: 10.1016/j.cub.2006.11.042

Hedstrom, K. L., and Rasband, M. N. (2006). Intrinsic and extrinsic determinants of ion channel localization in neurons. J. Neurochem. 98, 1345-1352. doi: 10.1111/j.1471-4159.2006.04001.x

Hines, M. L., and Carnevale, N. T. (1997). The NEURON simulation environment. Neural Comput. 9, 1179-1209. doi: 10.1162/neco.1997.9.6.1179

Hodgkin, A. L., and Huxley, A. F. (1952a). Propagation of electrical signals along giant nerve fibers. Proc. R. Soc. Lond. B Biol. Sci. 140, 177-183. doi: 10.1098/rspb.1952.0054

Hodgkin, A. L., and Huxley, A. F. (1952b). A quantitative description of membrane current and its application to conduction and excitation in nerve. J. Physiol. 117, 500-544.

Hodgkin, A. L., and Huxley, A. F. (1952c). Currents carried by sodium and potassium ions through the membrane of the giant axon of Loligo. J. Physiol. 116, 449-472.

Hossain, W. A., Antic, S. D., Yang, Y., Rasband, M. N., and Morest, D. K. (2005). Where is the spike generator of the cochlear nerve? voltage-gated sodium channels in the mouse cochlea. J. Neurosci. 25, 6857-6868. doi: 10.1523/JNEUROSCI.0123-05.2005

Huxley, A. F., and Stampfli, R. (1949). Evidence for saltatory conduction in peripheral myelinated nerve fibres. J. Physiol. 108, 315-339.

Imennov, N. S., and Rubinstein, J. T. (2009). Stochastic population model for electrical stimulation of the auditory nerve. IEEE Trans. Biomed. Eng. 56, 2493-2501. doi: 10.1109/TBME.2009.2016667

Kanemasa, T., Gan, L., Perney, T. M., Wang, L. Y., and Kaczmarek, L. K. (1995). Electrophysiological and pharmacological characterization of a mammalian Shaw channel expressed in NIH 3T3 fibroblasts. J. Neurophysiol. 74, 207-217.

Kolaric, K. V., Thomson, G., Edgar, J. M., and Brown, A. M. (2013). Focal axonal swellings and associated ultrastructural changes attenuate conduction velocity in central nervous system axons: a computer modeling study. Physiol. Rep. 1:e00059. doi: 10.1002/phy2.59

Leterrier, C., Brachet, A., Fache, M. P., and Dargent, B. (2010). Voltagegated sodium channel organization in neurons: protein interactions and trafficking pathways. Neurosci. Lett. 486, 92-100. doi: 10.1016/j.neulet.2010. 08.079

Macica, C. M., von Hehn, C. A., Wang, L. Y., Ho, C. S., Yokoyama, S., Joho, R. H., et al. (2003). Modulation of the kv3.1b potassium channel isoform adjusts the fidelity of the firing pattern of auditory neurons. J. Neurosci. 23, 1133-1141.

Nave, K. A. (2010). Myelination and support of axonal integrity by glia. Nature 468, 244-252. doi: 10.1038/nature09614

Novakovic, S. D., Deerinck, T. J., Levinson, S. R., Shrager, P., and Ellisman, M. H. (1996). Clusters of axonal $\mathrm{Na}+$ channels adjacent to remyelinating Schwann cells. J. Neurocytol. 25, 403-412. doi: 10.1007/BF02284811

Oertel, D., Shatadal, S., and Cao, X. J. (2008). In the ventral cochlear nucleus Kv1.1 and subunits of HCN1 are colocalized at surfaces of neurons that have lowvoltage-activated and hyperpolarization-activated conductances. Neuroscience 154, 77-86. doi: 10.1016/j.neuroscience.2008.01.085

Peles, E., and Salzer, J. L. (2000). Molecular domains of myelinated axons. Curr. Opin. Neurobiol. 10, 558-565. doi: 10.1016/S0959-4388(00)00122-7

Poliak, S., and Peles, E. (2003). The local differentiation of myelinated axons at nodes of Ranvier. Nat. Rev. Neurosci. 4, 968-980. doi: 10.1038/nrn1253

Poma, R., Chambers, H., da Costa, R. C., Konyer, N. B., Nykamp, S., Dobson, H., et al. (2008). MRI measurement of the canine auditory pathways and relationship with brainstem auditory evoked responses. Vet. Comp. Orthop. Traumatol. 21, 238-242.

Ranvier, L. (1871). Contributions à l'histologie et à la physiologie des nerfs périphériques. CR Acad. Sci. 73, 1168-1171. 
Rasband, M. N., and Trimmer, J. S. (2001). Developmental clustering of ion channels at and near the node of Ranvier. Dev. Biol. 236, 5-16. doi: 10.1006/dbio.2001.0326

Rasband, M. N., Trimmer, J. S., Schwarz, T. L., Levinson, S. R., Ellisman, M. H., Schachner, M., et al. (1998). Potassium channel distribution, clustering, and function in remyelinating rat axons. J. Neurosci. 18, 36-47.

Rattay, F., Lutter, P., and Felix, H. (2001). A model of the electrically excited human cochlear neuron. I. Contribution of neural substructures to the generation and propagation of spikes. Hear. Res. 153, 43-63. doi: 10.1016/S03785955(00)00256-2

Smit, J. E., Hanekom, T., van Wieringen, A., Wouters, J., and Hanekom, J. J. (2010). Threshold predictions of different pulse shapes using a human auditory nerve fibre model containing persistent sodium and slow potassium currents. Hear. Res. 269, 12-22. doi: 10.1016/j.heares.2010.08.004

Sterratt, D., Graham, B., Gillies, A., and Willshaw, D. (2011). Principles of Computational Modelling in Neuroscience. Cambridge, UK: Cambridge University Press. doi: 10.1017/CBO9780511975899

Tagoe, T., Barker, M., Jones, A., Allcock, N., and Hamann, M. (2014). Auditory nerve perinodal dysmyelination in noise-induced hearing loss. J. Neurosci. 34, 2684-2688. doi: 10.1523/JNEUROSCI.3977-13.2014
Toesca, A. (1996). Central and peripheral myelin in the rat cochlear and vestibular nerves. Neurosci. Lett. 221, 21-24. doi: 10.1016/S0304-3940(96) 13273-0

Conflict of Interest Statement: The authors declare that the research was conducted in the absence of any commercial or financial relationships that could be construed as a potential conflict of interest.

Received: 18 March 2014; paper pending published: 26 May 2014; accepted: 12 July 2014; published online: 01 August 2014.

Citation: Brown AM and Hamann M (2014) Computational modeling of the effects of auditory nerve dysmyelination. Front. Neuroanat. 8:73. doi: 10.3389/fnana. 2014.00073

This article was submitted to the journal Frontiers in Neuroanatomy.

Copyright (c) 2014 Brown and Hamann. This is an open-access article distributed under the terms of the Creative Commons Attribution License (CC BY). The use, distribution or reproduction in other forums is permitted, provided the original author(s) or licensor are credited and that the original publication in this journal is cited, in accordance with accepted academic practice. No use, distribution or reproduction is permitted which does not comply with these terms. 